\title{
Tectonic Hazards and its Effect on Man and Environment
}

\author{
Kaushik K Ghosh \\ Department of Geology, Jogamaya Devi College, Kolkata 700075
}

\begin{abstract}
Plate tectonics is the most significant geodynamic force operating within the Earth since after the formation of the crust. It is a branch of Geology which deals with the large-scale movement which is observed on the earth's surface. Volcanic eruption, earthquake and tsunami - these are the three hazards associated with tectonic movement. An attempt has been made in this study to identify the effective solutions to prevent, control and mitigate these hazards. "Prevention is better than cure" - this policy is not effective for any tectonic disaster. Problems can be minimized with the help of proper knowledge, awareness campaign and hazard preparedness. Due importance should be given to the uncoded knowledge of aborigines and local people.
\end{abstract}

Keywords: Plate tectonics, tectonic hazard, volcanic hazard, Earthquake and Tsunami

\section{Introduction}

Plate tectonics is the most significant geodynamic force operating within the Earth since after the formation of the crust. By definition, hazard is an unwanted, unavoidable situation or any source of potential damage on something or someone. Tectonic hazards are naturally occurring physical phenomena caused by the collision of lithospheric plates which form the enveloping surface of the earth and are always moving with different velocities on the asthenospheric substratum. This tectonic activity on earth can produce different types of extreme natural events or processes like volcanic eruption, earthquake and tsunamis and other types of secondary hazards like land slide, tectonic flood, fire etc. which are caused in connection with those tectonic hazards. On a global scale, the significance of the earthquake, volcanic eruption and tsunami hazards is emphasized by the fact that approximately 70 percent of the world 's 100 largest cities, accommodating 10 percent of the global population, are exposed to potentially damaging intensities of one or more of these hazard types (Degg, 1992a).

\section{What is Plate Tectonics?}

Plate tectonics is a branch of Geology which deals with the large-scale movement observed on the earth's surface. The lithospheric plates are roughly $100-125 \mathrm{~km}$ thick huge cover on the earth 's surface made up of the whole crust and the upper part of the upper mantle and spreads all over the global surface forming all the continental and oceanic blocks of the earth. The plates ,floate on the asthenosphere, a socalled hypothetical semi-molten soft layer, lies beneath them. The plates are always moving or sliding on the asthenosphere with different velocities. Therefore the boundary between plates are not stable. In one type of boundary two plates move towards each other - this is called collisional boundary or convergent plate boundary (Figs. 1 and 2A). In divergent plate boundary, two plates move away from each other forming a fissure in between (Figs 1 and 3). In third type, there is a fault between the plates and two plates pass each other along the plate boundary. This type of boundary is called transform fault boundary (Fig. 1). Most tectonic hazards are concentrated at plate margins although hotspots are notable exception. Melting of subducting slab along destructive plate boundary produce enourmous lava, creates volcanoes. Molten materials come into the surface along the fissure of the diverging plates and force related to tectonic strain gradually develops along the plate boundaries especially along fault and collision boundaries. So, different types of boundary generate different tectonic hazards.

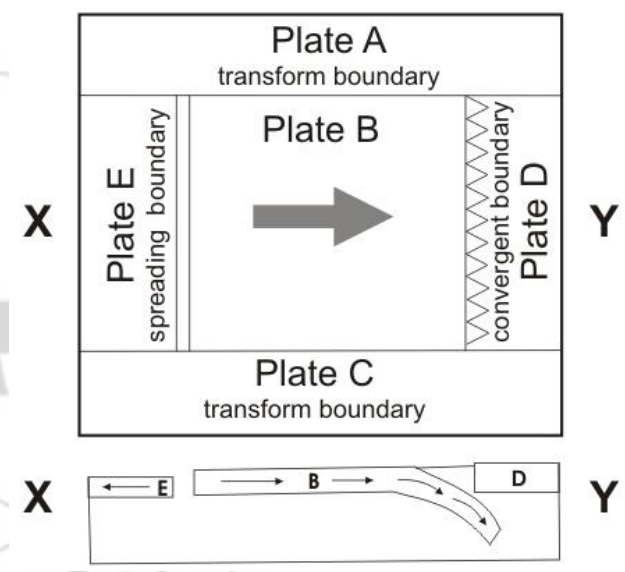

Figure 1

Plate tectonic model explaining different types of plate boundaries along the different margins of a hypothetical square plate (B).

Tectonic processes are driven by the heat generated due to radioactive decay within the earth"s interior. This heat set up vast convection cycle inside the earth which is responsible for the plate movement.

\section{Volcanic Hazard}

The cross section of a typical strato-volcanic cone is shown in the Figure 4. The common volcanic hazards are: (a) Lava flow, (b) Ash fall, (c) Glowing cloud, (d) Direct blast, (e) Lahar (volcanic debris and mudflows), (f) volcanic gases, (g) volcanic earthquakes, (h) tsunami (Large sea waves) and (i) ash clouds endangering aircraft. All the materials, under different conditions, either can endanger normal day-to-day life of local people or causes a major destruction on human settlement and surrounding environment. 


\section{International Journal of Science and Research (IJSR) \\ ISSN (Online): 2319-7064}

Index Copernicus Value (2013): 6.14 | Impact Factor (2015): 6.391

Lava flows are most common volcanic problem where property loss is an important consideration. In general, the life-loss is very uncommon in this situation as it is a channelized dense flow with slow velocity. Explosive eruption bears more silica than non-explosive eruption. Generally velocity of the lava flow is inversely proportional to the viscosity of the lava which is again a function of silica content of the melt. Basaltic lava is low in silica and hence low in viscosity and forms from the dry partial melting of upper mantle material. This type of lava flows to a great distance and is common in hot spots like Hawaii Island. This lava is also common in divergent plate boundaries, but all those boundaries are present in mid-oceans and forms midoceanic ridge (MOR). The notable exception is Iceland where MOR passes through the continental part and hence thin lava flow is common in this fissure eruption. The subducting plates in the collisional boundary melts partially in wet condition and forms volcanic chains along the continental margin of the Andean type shore line. This melt is comparatively rich in silica and forms intermediate type andesitic lava flows which form layered strata of alternating lava flows and pyroclastic flows with ash and tephra. Mud flow (lahar) and gas emission are quite common during eruption. This type of topography is available in continentocean collision boundary and good examples are most of the volcanoes of Andes mountain chain. Island arc margin (ocean-ocean collision boundary) like Japan volcanic arc is another example where intermediate lava flows are very common. Dangerous volcanic hazards are observed along the subduction zone at destructive plate margins. Highly viscous rhyolitic lava with high gas content cannot flow and is formed in situ from the melting of lower crust. Hazardous explosion is quite common with the generation of huge pyroclastic material is characteristic of this volcanic event. This is the deadliest type of eruption on the earth 's surface.

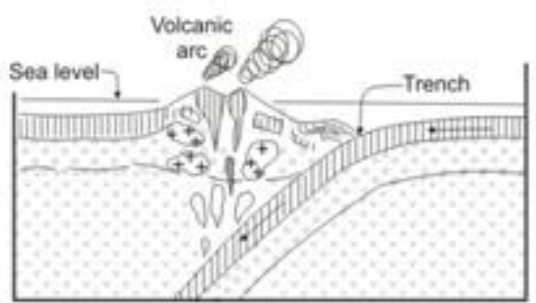

A

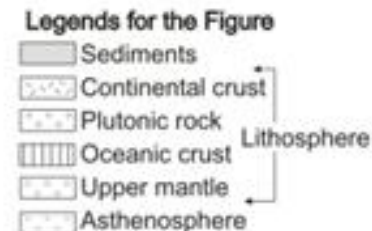

Figure 2

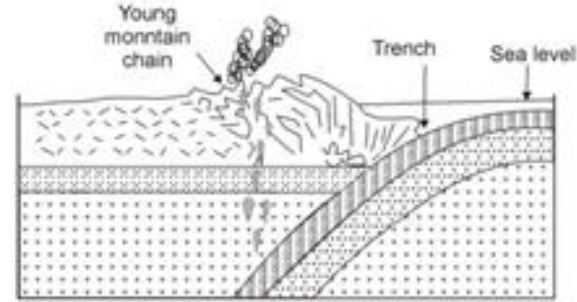

B

A. Convergent plate boundary between oceanic plates forming island arc setting. B. Convergent plat boundary between continental block and oceanic block. Note that

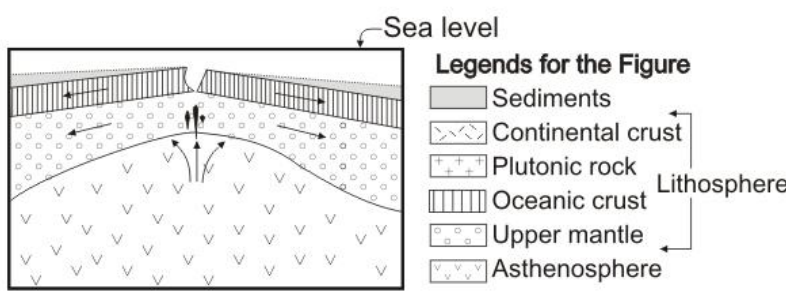

Figure 3

Divergent plate boundary between two oceanic block.

Pyroclastic materials are rock fragments or fall-outs from volcanoes which are either broken rock fragments from the sealed volcanic vents which reopens during eruption or ejected lava which travels through air, cools down and settle on the land as solid spherical mass. These ejectas causes accidents when they directly hits the human body. Different types of tephra and pyroclastics are may be either irregular (like volcanic breccia, pumice or solidified scum from the surface of the lava and scoria or ejected material of a cindery or slaggy nature) or spherical [like lapilli (diameter: $6-25 \mathrm{~mm})$, volcanic bombs $(>25 \mathrm{~mm})$ and tuff $(<4 \mathrm{~mm})]$. More the size, more will be the momentum and therefore more the hitting power. The rock debris carried by the lateral blast at Mount St. Helens in 1980 had an initial speed of more than $250 \mathrm{mph}$, and it was still moving about $60 \mathrm{mph}$ near its outer limit about 15 miles from the volcano (Crandell and Nichols, 1989). It is observed that andesitic and rhyolitic lavas produce more pyroclasits than basalt. oceaninc plate move below the continental plate due to its high density.
Pyroclastic flows have two distinct part - the lower part contains more coarser and denser fraction rolls down along the slope of volcanic cone and the upper part characterized by a turbulent ash flow or ash cloud which rise above basal flow and spread uniformly over the volcanic periphery. Sometimes, the superheated steam and volcanically generated hot dust cloud moves downhill and burns all the vegetation and assets of its path. This is called nuees ardentes.

Ash can affect health, especially responsible for respiratory and bronchial problem. It can contaminate municipal supply-water, destroys vegetation, disrupt mobile-phone signals and starts fire followed by short-circuit power supply. Acidic ash can form aerosol mist, corrode metal and causes road accident followed by engine-failure due to poor visibility. Sometimes flight-track may be changed due to the same reason. Huge ash fall can overload roofs.

Volcanic gases contain water vapour, carbon dioxide, carbon monoxide, various oxides of nitrogen and sulphur, and fluorine, chlorine, boron and other unusual elements. Gases can destroy vegetation, corrode metals and affects health of man and animal mainly by injuring eyes, skins and respiratory system.

Large sustained eruptions eject into the atmosphere huge quantities of fine ash and sulfur dioxide $\left(\mathrm{SO}_{2}\right)$ gas that can affect global climate. Volcanic dust forms aerosols which 


\section{International Journal of Science and Research (IJSR) \\ ISSN (Online): 2319-7064}

Index Copernicus Value (2013): 6.14 | Impact Factor (2015): 6.391

reflects back the sunlight back into space, and thus may cause a global lowering of earth"s surface temperature.

Mudflow or lahar is mass of water-saturated pyroclastic debris that move downslope along the stream channel. So they are not as such dangerous as no one constructs building in the course of stream. However, it has enough power to burry or carry away the man-made structures and swipes out traces of vegetation and life. Melting ice from the valley glacier on the volcanic cone make the situation more complicated.

A large landslide or mass fall is very common with the volcanic eruption accompanied by earthquake. By monitoring the slopes of the volcano, scientists may be able to detect ground changes that increase the probability of a landslide. Lava flow and pyroclastic debris flow sometimes block the running stream and form a natural dam. This temporary dam may finally fill up with water and failure of dam due excess pressure of water end up with flash flooding in downstream areas.

It is easy to mark volcanic zones on the map and prepare a hazard map with different risk level. However it is not possible to predict exact time of a major eruption. The history of previous eruption along with an understanding of the type of activity leads us to a statistical prediction. No one can stop volcano to erupt. In the terminology of volcanic activity, protection means monitoring of the volcano and evacuation from the area under threat. Such monitoring includes observations of land swelling, earthquake activity, changes in groundwater level and chemical composition, emission of gases, magnetic field studies and the shock wave analysis of the associated quake. We can use Volcanic Explosivity Index (VEI) to measure volcanic power for further reference.

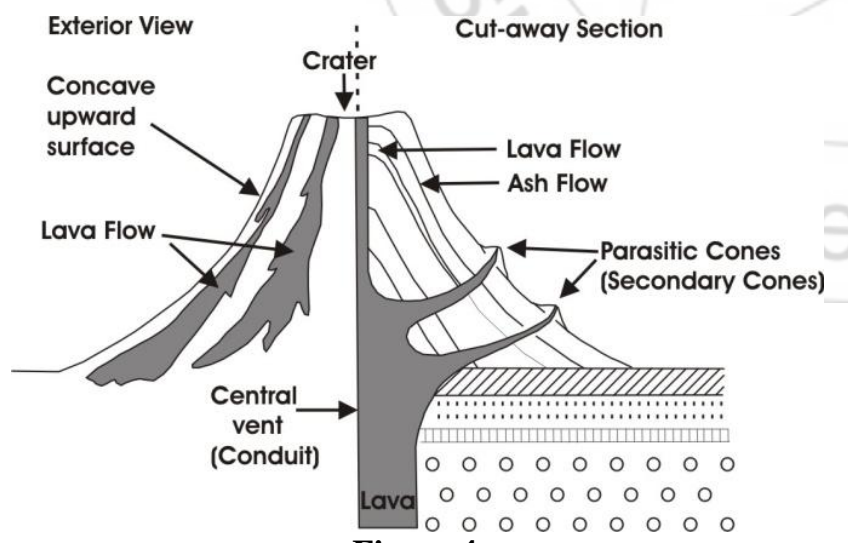

Figure 4

The internal (right side) and esternal (left side) view of a typical strato volcano showing different components of it.

\section{Earthquake and Tsunami}

Earthquake hazards include surface rupture and damage of construction related to vigorous shaking, liquefaction, landslides, and tsunami. Earthquakes are a very common, sudden release of energy along the active fault that generate seismic waves. Tectonic forces build up strain along the fault plain which is released abruptly when crosses a threshold value. When the same thing happens within the oceanic crust large oceanic waves accompany the vibration which is called tsunami. The example is the Asian Tsunami of 2004. When a tsunami approaches towards coastline, its amplitude increases in expense of its wave length and finally attains a height of more than 30 metres when hits the coast.

The remediation of earthquake has two parts - prediction and protection. Predicting earthquake is very difficult, especially short-term prediction. Regions of risk can be identified from the knowledge of plate tectonics and previous historic record and long term statistical prediction with different computer model is a fascinating trend now-adays. Monitoring groundwater levels, release of radon gas and unusual animal behaviour, however, give some clues for short-term prediction. Town planning with hazard zone mapping can minimise the property loss. Intensive studies along fault lines can sometimes indicate the zone along the fault where the next earthquake might occur.

"Prevention is better than cure" - this policy is not effective for any tectonic disaster. However, scientists are engaged in minimising the earthquake. Earthquake means sudden release of accumulated tectonic forces. So more frequent the earthquake less will be the stored energy and less will be the devastation. So, injecting waste water as lubricant along the locked fault plain may be an effective solution for controlling the earthquake. Earthquake hits on an area suddenly and violently without any prior sign. So understanding of earthquake through mass education and awareness campaign can minimise the earthquake risk. Earthquake resistant civil-engineering design and construction technique minimise the structural collapse. Applying rubber shock absorber in foundation and crossbracing concrete beam are the common among the structural measures. NCC or NSS students in India may be trained up with first-aid knowledge so that they may be engaged during medical emergencies. Land-use planning, avoiding active fault zones for construction purpose and insurance and aid reduce the earthquake hazard. "Dos and Don "ts" of earthquake published by different government authorities and rescue teams are:

A. Store adequate potable water which is sufficient at least for 3 days.

B. Keep first-aid kit and some necessary tools like radio, torch, batteries, matches, small fire extinguisher and pliers.

C. Quickly turn off all stoves and heaters and Get under a table or desk to protect yourself.

D. Do not run outdoors where you are liable to be hit by falling objects. However, those who lives under the roof of loose tiles, which is common in rural India, should leave home immediately.

E. Do not panic and walk to emergency evacuation areas. Do not be moved by rumours. Listen to local news over the radio.

F. Driving car during earthquake is not wise which causes accidents.

Liquefaction occurs when certain, usually saturated, soils and sediments lose their bearing strength during earthquake shaking. It is an important seismic hazard that has caused 


\section{International Journal of Science and Research (IJSR) \\ ISSN (Online): 2319-7064}

Index Copernicus Value (2013): 6.14 | Impact Factor (2015): 6.391

extensive damage to buildings, bridges and dams that result in little or no lateral displacement. Preparation of liquefaction hazard map and avoiding the over-saturated soil for large construction is the only solution for the problem.

In urban areas rupture of gas pipe-line network causes fire. Contamination of sewage water with municipal supply water may invite a situation like epidemic. Care should be taken for after-quake disaster.

A tsunami is a train of waves typically generated during an earthquake by sudden displacement of the sea floor or lakebed. Most tsunamis are caused by earthquakes but others are generated are due to the volcanic activities and, in few cases, by landslides, undersea slumps, or meteor impacts. Tsunamis have the potential to cause significant casualties, widespread property damage, massive infrastructure loss, and long-term negative economic impacts. India witnessed tsunami on $26^{\text {th }}$ December 2004. An earthquake of over 9.0 on the Richter scale hit $160 \mathrm{~km}$ off the west coast of Sumatra in the northern reaches of Indonesia. The release of accumulated energy along Sumatra Fault was responsible for a huge fault movement which causes earthquake and eventually the tsunami. Coastal tract and shorelines are the major affected areas of tsunami. There might be no harm or loss if we predict tsunami in time and the peoples be evacuated from the sea beach. Therefore, warning system plays an important role here. However, Tsunami prediction is very complex in nature and depends on exhaustive knowledge of computer simulation and modelling and their application on seismology and oceanography. Preparing regional tsunami hazard map and evacuation maps are very important for achieving the desired goal.

\section{Conclusion}

The important aspects, essential to mitigate the risk from tectonic hazards, are the identification of high-risk tectonic zones. Emphasis should be given in hazard identification, assessment, and zonation. Engineering and structural measures are to be taken in proper time. Emergency hazard preparedness and management can minimize the disaster. Rescue groups with proper training can play major role in this point. Most of the tectonic hazards can not be controlled or minimized due to lack of proper knowledge about them.

Not a single information of death was found from the Jarowas of Andaman and Nicobar Islands during Asiatic Tsunami of 2004. They have had their indigenous knowledge to solve the problem of tsunami. Due importance should be given to these uncoded knowledge of aborigines and local tribal people. Safe locations are to be marked and rescue centres and hazard preparedness system should be built up because move to the safer locations is better than taking an attempt to prevent tectonic earthquake. A special, designed lifestyle may be followed or adopted to cope-up with the hazards. Tsunami can be control by coastal defences through engineering measures. Lava dispersion at the time of eruption can minimize volcanic destruction. Earthquake event can not be stopped completely or changed.

\section{References}

[1] Degg, M.R. 1992a. The ROA Earthquake Hazard Atlas Project: recent work from the Middle East. In G.J.H, McCall, D.J.C. Laming \& S.C. Scott (eds.), Geohazards, natural and man-made: 93-104. London: Chapman \& Hall

[2] Crandell, D. R. \& Nichols, D. R. (1989). Volcanic hazards at Mount Shasta, California. U.S. Geological Survey General Information Product, $22 \mathrm{p}$.

[3] http://pubs.er.usgs.gov/publication/70039409

\section{Author Profile}

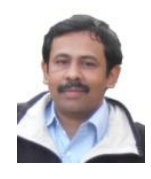

Mr. Kaushik K Ghosh received M.Sc. degree from the University of Calcutta, Kolkata and has submitted for Ph.D. degree from the same university. He is presently working as an Assistant Professor of Jogamaya Devi College, Kolkata. His research interest includes banded iron formation (BIF) and related iron ore deposits of India. He has published several papers in national and international journals.

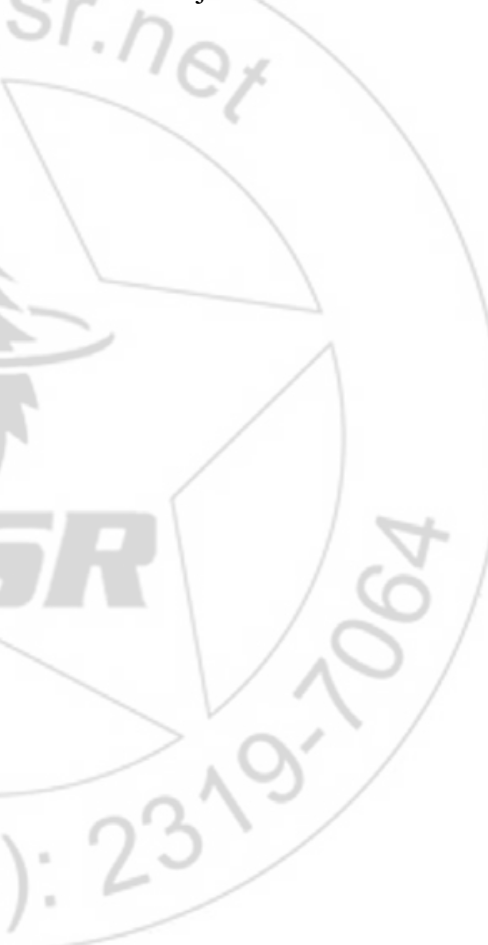

